\title{
O BILINGUISMO DO TRADUTOR
}

Angela Jesuino Ferretto

Em que sentido a tarefa do tradutor pode ajudar a esclarecer a questão do bilinguismo, e da subjetividade nele incluída? Ou, mais precisamente, o que nos ensina o bilinguismo do tradutor, na sua relação com o texto?

Eis a questão que gostaria de examinar hoje, a partir da prática de tradução de Lacan, uma prática que devo, por um lado, ao grupo trilingue (francês, português, espanhol), criado pelo Cartel de l'Amérique Latine em 1995 e dedicado à tradução de Lituraterre, ${ }^{1}$ e, por outro lado, aos colegas do grupo de tradução francês/português que, dando seguimento a esse primeiro trabalho, traduziu a Troisième, ${ }^{2}$ que acaba de ser publicada no Brasil.

Os tradutores profissionais certamente não concordariam com o que pretendo dizer aqui hoje, mas também para nós - tradutores improvisados da psicanálise - toda tradução já é uma teoria da tradução, e é portanto nosso dever pensar essa tarefa a partir das contribuiçôes da teoria lacaniana da linguagem, ou seja, a partir do discurso psicanalítico.

Gostaria de abordar essa questão a partir de duas observações, que surgiram da minha prática. A primeira é a seguinte: $o$ bilinguismo do tradutor é variável. Num primeiro momento, examinarei as condições dessa variabilidade.

Minha hipótese é que o bilinguismo do tradutor varia em função da posição subjetiva do tradutor nas duas línguas. A tradução depende dessa posição, uma posição que não está petrificada, que pode mudar. E é essa posição subjetiva em relação ao Outro da língua que vai determinar a forma como o tradutor privilegiará a língua fonte ou a língua-alvo (termos do jargão de tradutor pertinentemente criticados por Henri Meschonnic).

\footnotetext{
${ }^{1}$ LACAN, Jacques. D'un discours qui ne serait pas du semblant. Seminário inédito, lição do 12 de maio de 1971. Texto publicado em outubro deste mesmo ano no $\mathrm{n}^{\circ} 3$ da revista "Littérature" consagrada ao tema "Literatura e Psicanálise".

${ }^{2}$ LACAN, Jacques. Conferência feita em Roma em novembro de 1974 por ocasião do Congresso da Ecole Freudienne de Paris: O Real, a ética, a supervisão. In: Interventions de J. Lacan extraites des Lettres de l'Ecole. Documento de trabalho, Association freudienne internationale.
} 
Podemos nos perguntar sobre a forma de traduzir quando o tradutor está imerso em sua língua materna, quando a língua $\mathrm{Ou}$ tra é não apenas uma língua estrangeira mas também uma língua do mestre que não deve ser traída. A tradução pode se revelar então boba e disciplinada. É o caso de algumas traduçóes de Lacan em português, repletas de galicismos, de palavras em francês entre parênteses e incontáveis notas de pé de página. Falo aqui com conhecimento de causa pois foi nessa posição que traduzi La naissance de l'Autre. Com esse belo título, inaugurei o que, ao longo dos anos, foi-se revelando um verdadeiro corpo a corpo literal.

Uma outra situação é a do tradutor que deixa o seu país, sua língua materna, e torna-se tradutor no país para o qual imigrou. Nesse caso, será que o melhor que ele poderia fazer não seria justamente fazer-se adotar por esse Outro da língua, ao qual agora ele deve se dirigir? Será que o melhor que ele poderia fazer não seria então lhe declarar seu amor, mesmo que o preço a ser pago por isso seja que o texto na sua língua materna se torne letra morta? Seria por essa razão que aceitei traduzir, pouco depois de chegar à França, l'Amour de la langue de Jean Claude Milner?

O que se torna a tradução quando o tradutor faz análise na língua da imigração? Quando algo da dívida ao Outro se paga também nessa língua, e que, para além da declaração de amor, uma subjetivação passa também a ser possível? Quais são os efeitos na tradução desse tipo de bilinguismo que passa pela língua da análise?

O que tento mostrar através dessas questóes um tanto abruptas é o fato de o bilinguismo do tradutor ser tributário da relação do sujeito com o Outro, e que é essa relação com o Outro que determina a variabilidade desse bilinguismo, para além das questões relacionadas ao conhecimento das línguas, e de toda teoria construída a partir do velho debate em torno do privilégio a ser concedido à línguaalvo ou à língua fonte, como já mencionado anteriormente.

Essa primeira observação dá conta do aspecto imaginário, ou da imaginarização desse lugar Outro, aspecto esse que, por ter consequências, não deve ser menosprezado.

A segunda observação a ser feita é que o bilinguismo do tradutor tem como característica particular o fato de ser confrontado de maneira mais imediata à escrita, ao texto e, dessa forma, à questão da instância da letra.

Foi o exercício de tradução do texto Lituraterre que abriu um campo de trabalho completamente diferente do anterior. Isso se 
- (WAHL, François. "La mise en page de la psychanaly$\mathrm{se}^{\prime \prime}$. La célibataire ${ }^{\circ} 6$. Paris: EDK, 2002: 281)

(Ibidem: 282.)

-(Cf. RONAI, Paulo. A Tradução Vivida. Col. Logos. Rio de Janeiro: Nova Fronteira, 1981: 196.)

- (MESCHONNIC, Henri. Poétique du traduire. Paris: Verdier, 1999: 29)

(SVENBRO, Jesper. Phrasikleia. Paris: La Découverte,1988: 53-72) deve sem dúvida alguma, por um lado, ao próprio texto, mas, por outro, é consequência do método de tradução implementado. Enfatizo aqui dois aspectos em especial: essa tradução foi feita a muitas mãos, em grupo, $\mathrm{e}-$ aspecto ao meu ver muito importante - o texto era lido, em voz alta, nas três línguas referidas.

O texto de Lacan demanda tal leitura por conta do seu próprio estilo, "uma escrita que não poupa a fala, que utiliza constantemente o que se pronuncia, mais do que o que se lê". * Para Lacan, "a fala, o dizer, é preponderante em relação ao escrito, ou mais exatamente, o escrito é ele próprio um dizer". *

Mas não somos os únicos a ler em voz alta para traduzir. Esse método aproxima o nosso trabalho do de alguns tradutores de textos literários. Paulo Ronai, por exemplo, traduziu as mil e duzentas páginas da Comédia Humana de Balzac utilizando essa mesma abordagem.*

Aproximamo-nos assim também de Henri Meschonnic, segundo quem "num texto literário é a oralidade que deve ser traduzida"*

Mas o que faz o tradutor quando dá voz ao texto, quando empresta a sua própria voz ao texto?

Farei aqui referência aos estudos sobre a antropologia da leitura na Grécia Antiga, e em especial a Jesper Svenbro, que em seu livro Phrasikleia ${ }^{*}$ destaca elementos que nos poderão ser úteis aqui. Num capítulo dedicado ao leitor e à voz leitora, o primeiro ponto sublinhado pelo autor é que o escrito é incompleto se a ele não for acrescentada uma voz, e que a leitura em voz alta faz parte do texto, ela está inscrita no texto.

Uma outra observação diz respeito ao leitor. E, mais uma vez, a posição do autor pode nos interessar. E ele é incisivo:

- O leitor deve ceder sua própria voz ao escrito.

- No momento da leitura a voz não pertence ao leitor.

- O leitor permanece instrumental. Ao ler ele se define como $o$ instrumento sonoro da escrita.

- A voz deve seguir o rastro da escrita. O leitor segue os sinais tangíveis da escrita para guiar a sua voz.

- A voz do leitor é instrumento que distribui aos ouvintes - e também a ele próprio - o conteúdo do texto. Graças à sua voz ele poderá levar aos seus próprios ouvidos as palavras da inscrição.

Esse trabalho em grupo em torno do texto Lituraterre nos ensinou a ler, a levar aos nossos próprios ouvidos as palavras da ins- 
crição. Aprendemos também que para traduzir é preciso começar por ceder algo, por ceder sua própria voz ao texto.

O trabalho de tradução se transforma radicalmente com a introdução da voz objeto a - objeto de gozo - e com o endereçamento que essa leitura restitui. No entanto, dar a voz não basta. É preciso ainda que essa voz não seja uma pura substância de gozo e que ela possa também servir como vetor para a letra.

Se cada língua organiza o seu próprio recalque no ponto em que letra e voz se articulam, o tradutor não pode fugir ao exercício dessa articulação. Sobre isso, gostaria de dar alguns exemplos práticos de maneira a mostrar o que pode ser o trabalho do tradutor nessa articulação. Submeto assim essa tradução à crítica dos leitores. Trata-se de uma frase de Lacan em a Troisième:

"Je pense donc je souis", que traduzimos por: Penso logo gossou.

Descreverei aqui as etapas que nos levaram a optar por essa tradução: Jouir $=$ gozar e suis $=$ sou.

Diante do neologismo de Lacan, poderíamos permanecer num estado de sideração e optar por uma nota explicativa de pé de página. Mas fizemos uma escolha diferente. Partimos do passado do verbo gozar ("gozou") e forçamos a ortografia para encontrar nessa palavra o verbo ser conjugado na primeira pessoa: "gosou". Mas nessa escrita ("gosou") não se ouvia o verbo ser, o "sou". Podia-se ler, mas não ouvir, e com isso a versão em português acabava por enfatizar a parcela de "gozo". Ora, na escrita proposta por Lacan, o que se lê não é exatamente o que se ouve, mas o que ecoa nos ouvidos é antes de tudo o "suis". Para permanecermos fiéis a essa operação (aliás, a única fidelidade que podemos estampar), duplicamos o "s", de maneira a poder ouvir em português "gossou".

Nesse neologismo criado em português, buscamos seguir de perto o que foi operado por Lacan em francês, e logo não há decalque nem equivalência, mas antes uma operação da língua, um trabalho da letra.

Mas a questão que ainda nos preocupa é a dos efeitos de transmissão que esse tipo de tradução pode permitir, ou não. Fará ela transmissão ou resistência à psicanálise? Ainda não se pode saber.

Em todo caso, no que diz respeito à Troisième, nosso objetivo era o de restituir ao texto o seu caráter enunciativo. Restituir ao leitor brasileiro a virulência significante do texto de Lacan. Fabricar um texto em que as marcas desse trabalho de Lacan com a linguagem não fossem apagadas, de maneira que o leitor brasilei-
"(Cf. BERGÈS, Jean. “La voix aux abois". Discours Psychanalytique $\mathrm{n}^{\circ} 2$, Paris: J.Clims, 1989.) 
ro pudesse, como o francês, experimentar o mesmo sentimento de vacilação diante do texto.

Talvez sejamos obrigados a perceber, com Lacan, que a tradução não é apenas uma questão de passagem de uma língua à outra, um questão de equivalências, de fidelidade, de sentido, mas também de literalidade, de letra, e ao mesmo tempo de submissão ao significante e aos seus efeitos.

O bilinguismo do tradutor, por conta da sua relação com o texto, o obriga a um exercício de perda. Mas essa perda é da ordem do real da letra. Ou seja, isso não impóe ao tradutor adotar um posição de luto, mas sim constatar que o lugar do impossível é diferente em cada língua, o que o obriga, eventualmente, a inventar alguma coisa.

O bilinguismo do tradutor teria essa particularidade de ter que articular letra e voz, ter que navegar entre fala e escrita, entre um texto e outro. Seria portanto um bilinguismo marcado pela erosão da letra, pela voz como objeto a ceder e pelo gozo que o leva a recomeçar.

Percebam que eu deixei prudentemente o gozo para o fim. Porque essa prática da letra - ou por que não esse manuseio da letra? - é uma prática de gozo. Não sei no entanto se isso bastaria para dar conta da origem do gozo do tradutor. Seria essa articulação propriamente dita da letra? São por enquanto apenas questôes especulativas, cujo desenvolvimento ainda está por ser feito.

Uma última questão para concluir: o bilinguismo do tradutor o leva a saber o quê?

Em francês, diz-se: "impossível não é francês". Tenho vontade de dizer que também não é brasileiro, pois o impossível não é uma questão de língua, o impossível é uma questão de letra, portanto de efeito de discurso, uma questão que diz respeito à linguagem.

Isso o tradutor deve saber se não quiser permanecer atrelado ao que é o imaginário de cada língua.

tradução de Daniela Cerdeira 


\section{Angela Jesuino Ferretto}

Brasileira radicada em Paris, psicanalista membro da Association Lacanienne Internationale (Paris) e do Tempo Freudiano Associação Psicanalítica (Rio de Janeiro). Vários artigos publicados em francês, português e espanhol. No que concerne a questão da tradução: "Tradouire", "Le bilinguisme du traducteur", "Lacan deve falar português?”, “Tradouire, quel rapport au texte?”.

\section{Resumo}

O bilinguismo do tradutor é tributário da relação do sujeito com o Outro, o que vem determinar a variabilidade desse bilinguismo para além das questôes relacionadas ao conhecimento das línguas, e de toda teoria construída a partir do velho debate em torno do privilégio a ser concedido à língua-alvo ou à língua fonte.

O bilinguismo do tradutor é confrontado de maneira mais imediata à escrita, ao texto e, dessa forma, à questão da instância da letra. Isso o obriga a um exercício de perda que é da ordem do real da letra. Essa perda não implica adotar uma posição de luto, mas constatar que o lugar do impossível é diferente em cada língua, o que leva o tradutor, eventualmente, a inventar alguma coisa.

A experiência de tradução de Lacan no que ela exige levar em conta a "oralidade do texto" nos ensina que o bilinguismo do tradutor teria essa particularidade de ter que articular letra e voz, fala e escrita. Este bilinguismo seria portanto marcado pela erosão da letra, pela voz como objeto a ceder e pelo gozo que o leva a recomeçar.

\section{Abstract}

The translator's bilingualism is a result of his or her relationship with the Other, which ultimately determines the variability of such bilingualism beyond issues related to knowledge of languages and all theories based on the old debate on the privilege of the target or source language.

The translator's bilingualism is more immediately confronted with writing, with the text, and

\section{Resumé}

Le bilinguisme du traducteur est redevable de la relation du sujet à l'Autre ce qui détermine la variabilité de ce bilinguisme au delà de toute question liée à la connaissance des langues ou à toute théorie concernant le vieux débat autour du privilège à accorder à la langue cible ou à la langue source.

Le bilinguisme du traducteur aurait ceci de particulier d'être confronté à l'écrit, au texte et
Palavras-chave: bilinguismo do tradutor; posição subjetiva; letra; voz; psicanálise.

Key words: translator's bilingualism; subjective position; letter; voice; psychoanalysis.

Mots-clés: bilinguisme du traducteur; subjectivité; lettre; voix; psychanalyse. 
as such with the issue of the instance of the letter itself. This leads to an exercise in losing that partakes of the real of the letter. Such loss does not imply a position of mourning, but the acknowledgment that the location of the impossible is different in each language, which forces the translator to invent something on occasion.

The experience of translating Lacan in that it demands that one takes into consideration the "oral nature of the text" teaches us that the translator's bilingualism has this peculiarity of having to articulate letter and voice, speech and writing. This bilingualism is then characterized by the erosion of the letter, by the voice as an yielding object and by the enjoyment that makes the translator start afresh. du même coup à la question de l'instance de la lettre peutêtre d'une façon plus immédiate. Cela l'oblige à un exercice de perte mais cette perte est de l'ordre du réel de la lettre. Cette perte impose au traducteur non pas à adopter une position de deuil mais à constater que le lieu de l'impossible n'est pas situé à la même place dans chaque langue. Cela l'oblige le cas échéant à inventer quelque chose. L'expérience de la traduction de Lacan en ce qu'elle exige de prendre en compte « l'oralité du texte " nous apprend que le bilinguisme du traducteur a ceci de particulier, s'il y concède, d'avoir à articuler la lettre et la voix, la parole et l'écrit. Ce bilinguisme serait donc marqué par le ravinement de la lettre, par la voix comme objet à céder et par la jouissance qui le pousse à recommencer. 